\title{
Why Invest to Prevent Child Abuse? The Budgetary Impact of Direct, Indirect and Collateral Derived Costs
}

\author{
María Teresa Sotelo Morales* \\ Fundación En Pantalla Contra la Violencia Infantil, Mexico \\ *Corresponding author: María Teresa Sotelo Morales, President Fundación En Pantalla Contra la Violencia Infantil, Mexico

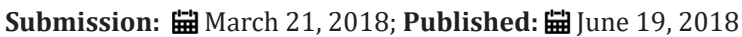

\begin{abstract}
Violence, and neglect in childhood, present innumerable economic costs to nations, whose impact on spending the public budget fluctuates between $15 \%$ and $25 \%$ of the annual government budget, as shown by several studies carried out in the United States, the European Union, and Mexico. The Center of Developing Child, of Harvard, emphazises that during the first years of life, the development of the brain can be physiologically altered by the prolonged and severe abuse of a child, over time, the brain of a 3 year old child, grows disproportionately large and heavy [1], reaching nearly $90 \%$ of the size of an adult brain. This alteration in the development of the brain can negatively impact the physical, cognitive, emotional and social development, whose consequences will always be present, even 30, 40 or 50 years later. International studies with significant data, are herein in summary presented. All in unison insists not only on preventing but on eradicating child maltreatment, considering this scourge as the determining element that havoc in government budgets. With an encourage exhortatory that by investing in preventing children from violence, a significant reduction in gross domestic product from 20 to $25 \%$ would be achieved [2].
\end{abstract}

Keywords: Child abuse; Economic burden; Lifelong consequences; Brain development

\section{Introduction}

The National Center for Disease Prevention and Control in Atlanta, published a research on the economic burden of child abuse in the United States, and the implications for prevention [2012]. The study provides a cross-sectional approach, based on the incidence of expenses resulting from the lifetime economic burden, that an infant victim of abuse and neglect represents for the country. The publication presents new findings regarding the analysis of 579,000 cases of non-fatal abuse, and 1,740 fatal cases of child abuse in the United States in 2008 [3]. It mentions that, on average, the cost of living is projected at $(\$ 210,012)$ per child victim non-severe abuse, and $(\$ 1,272,900)$, for victims of lifethreatening abuse. In summary, it suggests an estimated cost for the country, of 124 billion dollars per year for the direct, indirect and collateral costs of child abuse and neglect. The study presents an analogy of combined methods based on prevalence, versus the study elaborated by other colleagues Wang and Holton (2007) who point to an estimate of 103.8 billion annual costs, and justify the difference between one study and another, due to the fact that underestimates the total incidence of child abuse, because some of the results may not have been taken out for registration [4].

The American Journal of Preventive Medicine, presented a review of 12 articles that deal with the economic impact on health as a result of child abuse and trace the dynamics and structure of the studies noting that the greatest limitation in the current estimates of the rising costs for the care of children is that they do not consider the expenses arising outside hospitals; Prescription drugs and systematic studies for chronic diseases derived, also indicates that only the most serious cases of abuse require hospital care, and these are not a representative sample of the dimension of the problem $[5,6]$.

The diagnosis to indicate child maltreatment may underestimate the prevalence factor because must of the cases may go unnoticed, but the degree and direction of how it predisposes to innumerable economic expenditures is unknown. The study rely on these scientific discoveries for the formulation of economic and social policies [7].

The Prevent Child Abuse America Organization, in its publication the "Technical Guide to Estimated Annual Cost of Child Abuse and Neglect by "Kathryn Harding, MA, which in summary presents a total of direct costs of (\$US 33,333,619,510) to the country, and justifies it by means of a breakdown of expenses generated by medical treatment, hospitalization costs for injuries, traumatisms [8], fractures or other disorders, diagnosis and condition and derivatives; injuries, poisoning, burns, bruises, disabilities etc. It 
includes adult survivors of abuse who need some type of treatment linked to the mental health care system, resulting in $25 \%$ to $50 \%$ of the health expenditures. Likewise, the National Institute of Justice of United States in the 2012, estimates the costs for legal services in (\$US34, 279,048).

The scrutinity also analyzes and raises the multiple indirect costs derived and estimates them at \$US80 260, 411.087 reflected in $[9-12]$ :
A. Special education: $\$ 826,174,734$
B. Early intervention: \$ US164, 790,017
C. Shelters and transition houses: \$ US 1, 606, 866,538
D. Mental Health Services: US \$ 270, 864,199
E. Juvenile delinquency: US \$ 3, 416, 149,283
F. In adult criminal justice system: US \$ $32,724,767,699$
G. Low labor productivity: US \$ 7, 834,164, 589

H. Low labor productivity: US \$ 7, 834,164, 589

The condition of vulnerable children is a matter of concern for organizations such as the World Bank, which together with UNICEF developed a proposal called "Common Ground; UNICEF and World Bank [13-15], Approaches to Building Social Protection", the document raises the challenges of political economy, risks of excessive centralization, transaction costs and limited transparency in a joint effort to work in unison with government and civil society organizations for protecting family, community and childhood.

During the first years of life, the development of the brain can be physiologically altered by the prolonged and severe maltreatment of a child. Dr. Shonkoff [16], from Harvard University, adverts that over time, the brain of a child 3 years old, grows disproportionately large and heavy, reaching nearly $90 \%$ of the size of an adult brain. This alteration in the development of the brain can negatively impact the physical, cognitive, emotional and social Development, whose consequences will always be present, even 30,40 or 50 years later [17].

This, among other neuronal findings related to brain damage in an individual with antecedents of victimization in childhood, have taken courses that in other times would have seemed outrageous to us, as they rely on these scientific discoveries for the formulation of economic and social policies. The Harvard University since 2003, formed a national scientific council composed of a multidisciplinary team, with notable academics from various universities in the US and Canada, called "National Scientific Council on the Developing Child", which aims to bring legislators and political leaders, scientific findings regarding the impact of emotions on the development of early childhood [18], and the underlying trace in the brain of the individual, whose actions will permeate his life and that of others, as a domino effect. This council is made up of scientists from different fields; Neurology, immunology, molecular biology, endocrinology, psychology, economics, social policy and pediatric medicine.
In short, the Harvard initiative has been a powerful and intelligent process to design public policies, whose vision focuses on seeing the child as the future teenager and man of tomorrow [19]. It is the integration of policies in health, education and justice, with a global vision meticulously designed to achieve healthy individuals for a healthy society. The National System of Justice of the United States states [20], on its website points out, that having been a victim of abuse or abandonment in childhood, increases the probability of arrest for delinquent acts in adolescence by $59 \%$, and in adulthood by $28 \%$, indicates also that for committing violent crimes, this probability increases by $30 \%$.

The results of another study funded by the Office of Juvenile Justice and Crime Prevention suggest a strong relationship between child abuse and crime later. The Rochester study, carried out the follow-up of a thousand urban youths over time. The researchers found that child abuse, is the serious risk factor for delinquency, violence, alcohol consumption, and use of illicit drugs in early adulthood, and allude that women victims of abuse and neglect, during child-rearing are more likely to engage in criminal behavior.

Although the health consequences of child abuse are well established, relatively few studies to date, have estimated the associated health costs, and there have been no systematic reviews of these expenditures, which delimits the true dimension of the problem and all associated costs [21].

The analysis of mortality in children reflects the existence in Mexico, of high levels of sub-registry of $68 \%$ of death in children due to abuse derived from parental negligence of care in priority diseases derived from nutritional disorders, gastrointestinal, pulmonary and preventable diseases, $87 \%$ of deaths due to abuse are classified as accidental or indeterminate and, for each death [22], 9 are considered disabled, 71 children with serious injuries, and countless victims with psychological consequences. The death of the shaken baby and syndrome of sudden death, $68 \%$ of the cases are murders that go without further investigation (American Academy of Pediatrics).

According to OECD members. The National Report on Violence and Health made by UNICEF, Mexico and South Korea, have the highest rates of deaths from injuries in children under the age of 14 and ranks, first in the category of intentional deaths of children between 1 and 14 years old caused by their own parents. According to records of the Superior Court of Justice of the Federal District, in the years 2010 and 2011, declared half of the victims were children, and that in more than $90 \%$ of the cases the perpetrators were one or both parents [23].

\section{Study}

Taking as a starting point these referents, being as the Head of Fundación En Pantalla Contra la Violencia Infantil, known as FUPAVI, presented in 2014, to the media, various financial and statistical analyzes of the international studies indicated a qualitative and quantitative analysis of the budgetary impact in Mexico, of the expenses derived from child abuse, nevertheless it should be 
clarified that the expenditures that were indicated, was only an approximation to a reality, due to the absence of methodological antecedents with precise data that allow for a precise weighing of expenses, fundamentally, for the sub record in child deaths Figure 1.

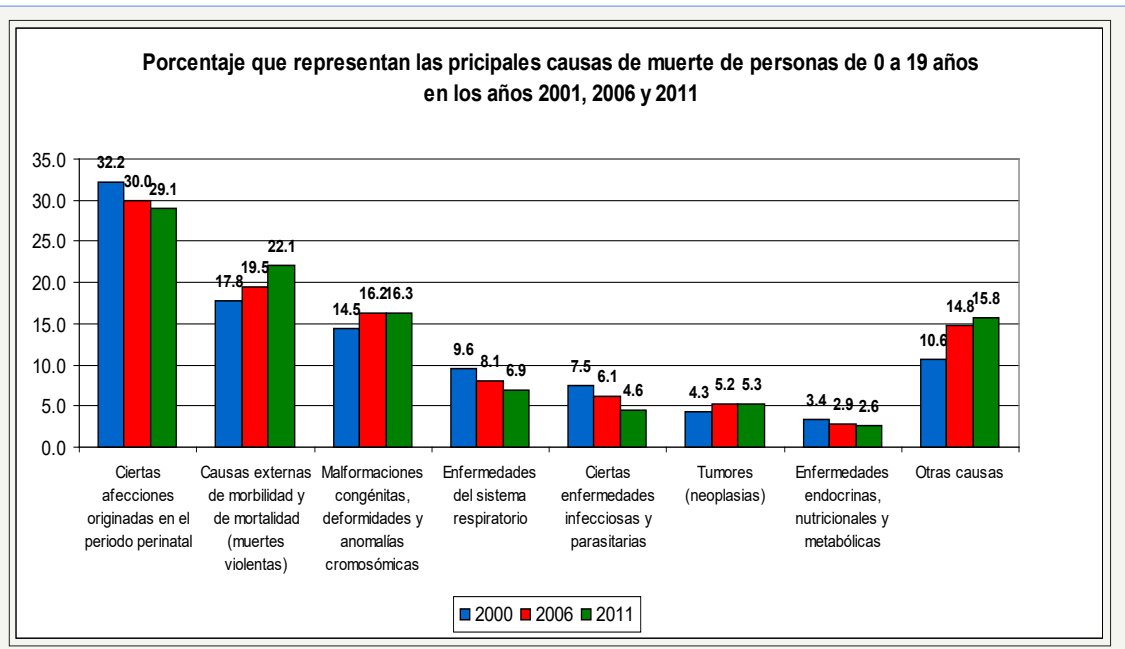

Figure 1: Main causes of death in people from 0 to 19 years of the years 2001, [blue] 2006 [red] and 2011 [green].

The expenses incurred by the government, related to child abuse have to do with: Health, application of the law, the legal system, education, crime, labor productivity, unemployment, etcétera. According Paulo Sérgio Pinheiro, in his World Report on Violence against Children published by United Nations in 2006, The respective sectors are involved in the following spenditures:

A. Medical: Prolonged treatments for sequelae, mental health programs; brain damage, personality disorders, posttraumatic stress syndrome, anxiety, suicide, self-inflicted injuries, and other psychiatric illnesses. Bruises, burns, depression fractures, eating and sleeping disorders, sexual dysfunction, addictions, teenage pregnancies, sexually transmitted diseases, special education, unwanted pregnancies, sequelae derived from Shaken Baby Syndrome as blindness, epilepsy, mental retardation and death. Figure 1 Percentages of the main causes of death from 0 to 19 years.

Source: Health

B. Civil attention: Child welfare programs, family care programs, shelters, temporary and emergency housing, etc.

C. Justice: Application of the Law, creation and expansion of prisons, damage by criminal acts, training of personnel, etcetera. Figure 2 Costs associated with juvenile delinquency in México 2013.

D. Work: low productivity, unemployment, etc.

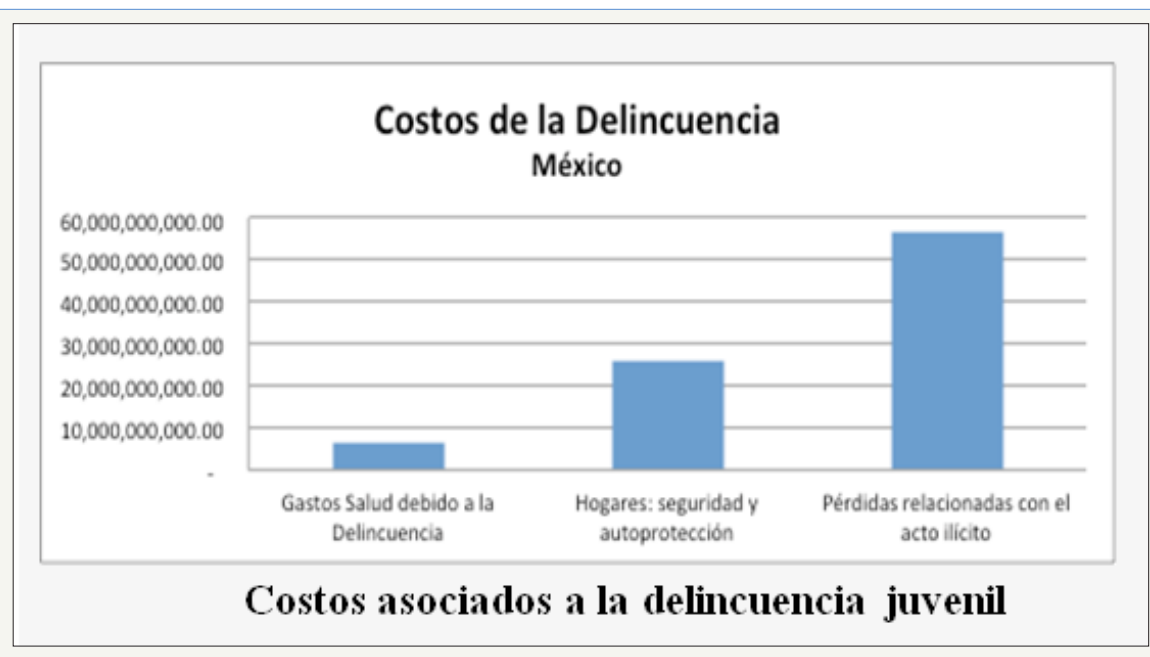

Figure 2

\section{Method}

The rigor in the study used by FUPAVI, to obtain the totals, it was taken from the Federal Budget of Expenditures 2014. Functional Economic Programmatic Analysis, as well from the
Reports on the Economic Situation of Public Finances and Public Debt, which estimated amount was of $\$ 55,258,715,617.00$, from cost derived from child abuse and neglect. [For this calculation, only the estimated inflation of $1.37 \%$ was considered. Factors related to 
the global economic situation, stability risks, economic growth and global projections were omitted, such as: The price of a barrel of oil, exchange rate of the dollar, international interest rate [24].

As relevant, it was found that the above referred federal budgets of 2013 and 2014, of the institutions [that should be involved in the prevention of child violence] such as Ministry of Social Development, Ministry of Health, Governance, Ministry of Public Education, and the Attorney General's Office of Justice, no budget was found mentioning the prevention of child abuse and neglect, only and repeatedly, the allocation of resources were assigned for "Preventing of violence at the female gender". In this regards, this is a global phenomenon, that has captured the attention of the governments to forbid women from violence, pushing aside the grave danger of excluding other sectors of the population, victimizing excessively the female sector, despite the statistical data point the prime perpetrators in the family core, the mother as the first homicide of the children, second the father, third place both parents, then, stepfather/stepmother, grandparents, uncles etcetera, In this order is indicated the study made by the Ministry of Public Security in May 2010. "Child Abuse and Abuse in Mexico: Risk Factor in the Commission of Crimes, finding coincidences in other international statistics, such as Canada, USA, and China.

However, It should be noted this study has no biased implications, only aims to redirect care to children as the sector that has been neglected, whose implications permeate all the structures of a nation.

\section{Discussion}

The methodology used in the international referred in this review, is conclusive regarding the serious impact budgetary burden in a nation of the expenses derived from the abuse, and abandonment in childhood. Without pretending to redound to the widely exposed concepts. There is no doubt that violence in the early stages, as a domino effect destroys the social context. The amounts indicated in the mexican budget examination by FUPAVI, are far less from the costs presented by other analogous publications of foreign hospitals and universities. Due that while analyzing the budget of expenditures of the mexican federation, there were consistently gaps in referential information that could have served as support to complete other costs that could not be contemplated, due the under registration in childhood illnesses and deaths, and the absence of validations in criminological and social studies based on reports of victims, and other perdiem derived from violence, which prevented adjusting methods and analysis of direct, indirect disbursement, as well as contingent, circumstantial and random expenses. Hence, the expenses incurred by the institutions had to be assumed, because none allocated budget for prevention or comprehensive attention to child abuse and neglect was found.

The study and data presented regarding the impact on the budget, although true in terms of its allocation, in the federation expenditure budget, they are a distant approximation to the true dimension of the impact of child abuse in the country. The factor that could privilege the value of this study is supported by presenting other international studies, which proposes investing in the public policy design, and allocate budget to the health, education, justice and social sectors, for the implementation of models of intervention to prevent and eradicate child violence, which would achieve savings in GDP of approximately $25 \%$, coupled with the privilege of achieving a just, equitable and healthy society [24].

\section{Conclusion}

The scientific advances of the neurosciences clearly demonstrate the brain damage in the victims of persistent violence during infancy, the impact will be present 30 , 40years later. This data is conclusive to understand why abuse in childhood is considered as the determining precursor in criminal behavior; in the mind of the suicide, drug addicts, and other pathogenic conducts, because at the end of the day, what matters is what gravitates in the mind of an individual, if he has disturbing impulses and thoughts, his behavior will be respectively disturbing. Understanding this does not imply any science, it is simple.

The attention to the phenomenon of child abuse has been generationally debated among public institutions, resulting in a problem in no man's land. The health sector attributes it to a problem of criminal sciences, the educational sector points it out as a medical problem, the legal sector as social concern etc. The situation is that no sector attributes the infant abuse in its scope of work. Notwithstanding the World Health Organization, recognises it is a public health scourge, that permeates all structures of a nation as demonstrated in this and other referred studies.

In my opinion, the medical sector is the first qualified institution to issue warning signals. The violence has to do with brain impulses or tumors, genetics, addictions, etc... That must be complemented by social studies of risk families. The challenge is to create preventive public policies, anticipating the phenomenon before it happens. Identifying children in vulnerable conditions, detecting families that generate violence, would be an intelligent measure. Why not include in the medical card the risk factors of child abuse? And create multidisciplinary and interdisciplinary teams in medical, and educational institutions to take charge of clinically and socially cases, addressing the possible victim, victimizer, and the family as a whole?

As primary preventing resource, the health sector could consider reversing the procedure as well, instead of just treating the patient, It might first look for patients susceptible to the violence, whether as victim or victimazer, by analizing all risk factors, as potentiall detonator of child abuse, considering all the medical disease implications of leaving a kid unprotected.

The systematic review could potentially support prevention efforts by seeking significant savings in public expenditure.

\section{References}

1. Delima, Jennifer, Vimpani, Graham (2011) The neurobiological effects of childhood maltreatment: An often overlooked narrative related to the long-term effects of early childhood trauma. Australian Government. Australian Institute of Family Studies. Family Matters No 89, Australia. 
2. Dolezal, Theresa MA (2009) Hidden costs in health care: the economic impact of violence and abuse. Academy of Violence \& Abuse.

3. Corso PS, Edwards VJ, Fang X, Mercy JA (2008) Health-related quality of life among adults who experienced maltreatment during childhood. Am J Public Health 98: 1094-1100.

4. Forjuoh SN (2000) Child maltreatment related injuries: incidence, hospital charges, and correlates of hospitalization. Child Abuse Negl 24(8): 1019-1025.

5. Understanding the Effects of Maltreatment on Early Brain Development (2015) National clearinghouse on child abuse and neglect. Information, Washington, USA.

6. Razuzta JE, McJunkin JE, Danadian K, Arnold F, Zhang J (1997) Outcome and cost of child abuse. Child Abuse Negl. National Center for Biotechnology Information, US National Library of Medicine. National Institutions on Health 21(8): 751-757.

7. Center on the Developing Child. National Institute of Justice.

8. World Health Organization. European report on preventing child maltreatment. Regional Office of Europe, Geneva, Switzerland.

9. http://www.euro.who.int/ data/assets/pdf_file/0019/217018/ European-Report-on-Preventing-Child-Maltreatment.pdf

10. Creative Commons License (2006) World report on violence against boys and girls, USA

11.https://www.unicef.org/mexico/spanish/Informe_Mundial_Sobre_ Violencia.pdf
12. Derek S Brown, Xiangming Fang, Curtis S Florence (2011) Medical costs attributable to child maltreatment systematic review of short- and longterm effects.

13. Kathryn Harding (2009) Technical guide to estimated annual cost of child abuse and neglect prevent child abuse america. Americ Journal of Preventive Medicine 41(6): 627-635.

14. (2007) Center on the developing child the impact of early adversity on child development (In Brief).

15. https://developingchild.harvard.edu/people/jack-shonkoff/

16.Xiangming Fanga, Derek S Brownb, Curtis S Florencea, James A Mercya (2012) The economic burden of child maltreatment in the United States and implications for prevention 36(2): 156-165.

17. Brown DS, Fang X, Florence CS (2011) Medical costs attributable to child maltreatment: A systematic review of short- and long-term effects. American Journal of Preventive Medicine 41(6): 627-635.

18. DeVooght K, Allen T, Geen Casey Federal R (2008) State and local spending to address child abuse and neglect in SFY 2006.

19. (2013) Budget of expenditures of the federation in Mexico, Mexico.

20. www.transparenciapresupuestaria.Gob.mx

21. www.transparenciapresupuestaria.Gob.mx

22. http://www.apartados.hacienda.gob.mx/inf_trim/2013/4to_trim/ docs/ane/anefp11.pdf

23. www.fundacionenpantalla.org
Creative Commons Attribution 4.0 International License

For possible submissions Click Here

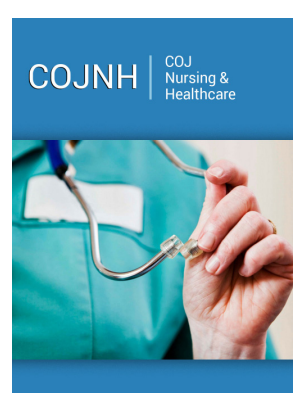

\section{COJ Nursing \& Healthcare}

Benefits of Publishing with us

- High-level peer review and editorial services

- Freely accessible online immediately upon publication

- Authors retain the copyright to their work

- Licensing it under a Creative Commons license

- Visibility through different online platforms 